\title{
AOR
}

Selected Papers of \#AolR2020:

The 22nd Annual Conference of the Association of Internet Researchers

Virtual Event / 13-16 Oct 2021

\section{EX NUGIS SERIA: THE INTERNET MEME AS CONTEMPORARY EMBLEM}

Author Name: Ray Drainville

Author Institution: Stratford School of Interaction Design and Busines, University of Waterloo, Canada

Extended studies of Internet memes situate them broadly under Dawkins' (1976) conception of the meme as a "cultural unit" of communicative information (Shifman, 2014; Milner, 2016; Wiggins, 2019), typically reducing a meme's visual aspect to a "visual 'action verb'" (Milner, 2016:68). I argue that an important parallel for understanding contemporary memes has been neglected: emblematic imagery arising from the early publishing culture of the European Renaissance. Below, I briefly describe several of these parallels.

\section{Formal presentation, multimodality, and juxtaposition}

There are currently four popular Internet meme formats that set up the viewer's expectations, in related ways: the image macro, the exploitable, the Photoshop meme, and the object label (and its variant, the captioned image: see Figure 1 for examples). The meme-maker frequently uses a pre-existing picture and usually pairs it with text, or alternately pairs one image with another image. The relevance of the image relies upon recognition: the viewer might be familiar with the subject matter (e.g., Bernie Sanders sitting during the Inauguration), or, alternately, substantially understand the poses, facial expressions, or gestures in the picture (e.g., the couple in the "Distracted Boyfriend" meme). 

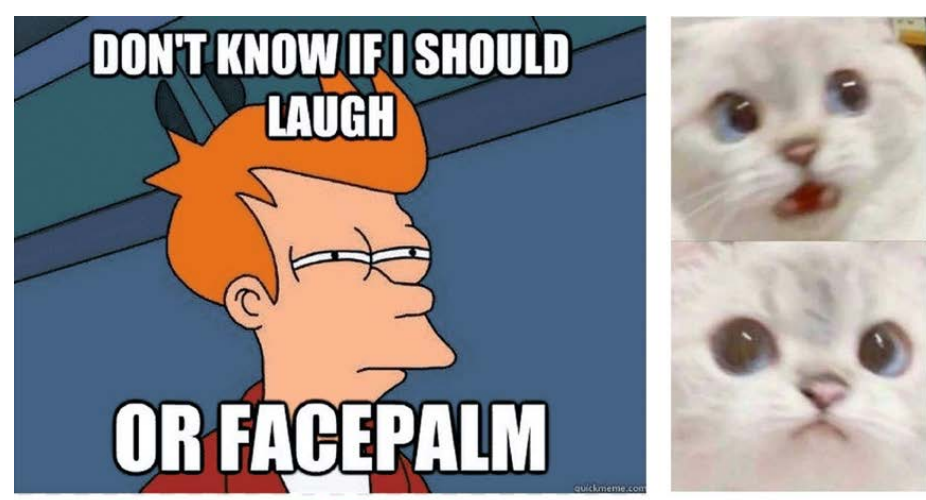

Schrodinger is putting you in a box
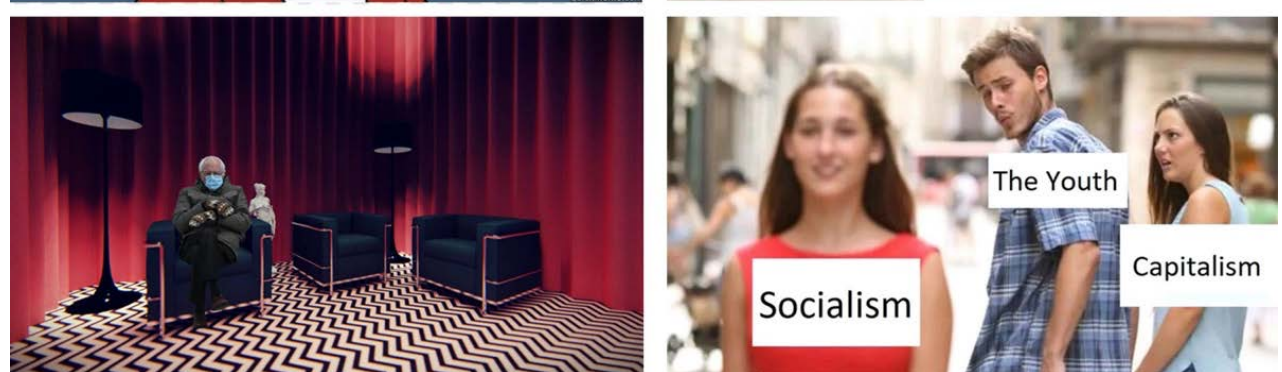

Figure 1: Four common meme types: the "image macro" (top left; a "Not sure if' Philip Fry from Futurama meme), the "exploitable" (top right), the "Photoshop meme" (bottom left; a "Bernie sitting" meme), and the "object label" (bottom right; a "Distracted Boyfriend").

Emblems are perhaps most closely associated with Andrea Alciato's 1531 Emblematum libellus, the popularity of which set the emblem to become a favored form of expression for centuries. Alciato's emblems took a dual multimodal form: a picture, usually containing a somewhat familiar figure, and an epigram, a pithy expository text that placed the image in an unexpected light, formally presented in a consistent, clear fashion. Thus, the picture is framed in such a way that separates it from its title and expository text (Figure 2). The physical juxtaposition of text and image already forms a striking parallel with the image macro, but the similarity runs deeper than this. Like memes, emblems were disjointed affairs where "the everyday or commonplace is changed by virtue of being placed in another context"; it is a "bearer of unsuspected meaning, a metonym for a previously hidden reality" (Manning, 2002:48). Alciato explained that the text provided the opportunity to provide "some elegantly-chosen significance" to the subject (Alciato, 1953:Letter 24). This imposition of text on image to provide new significance reflects memetic practices. 


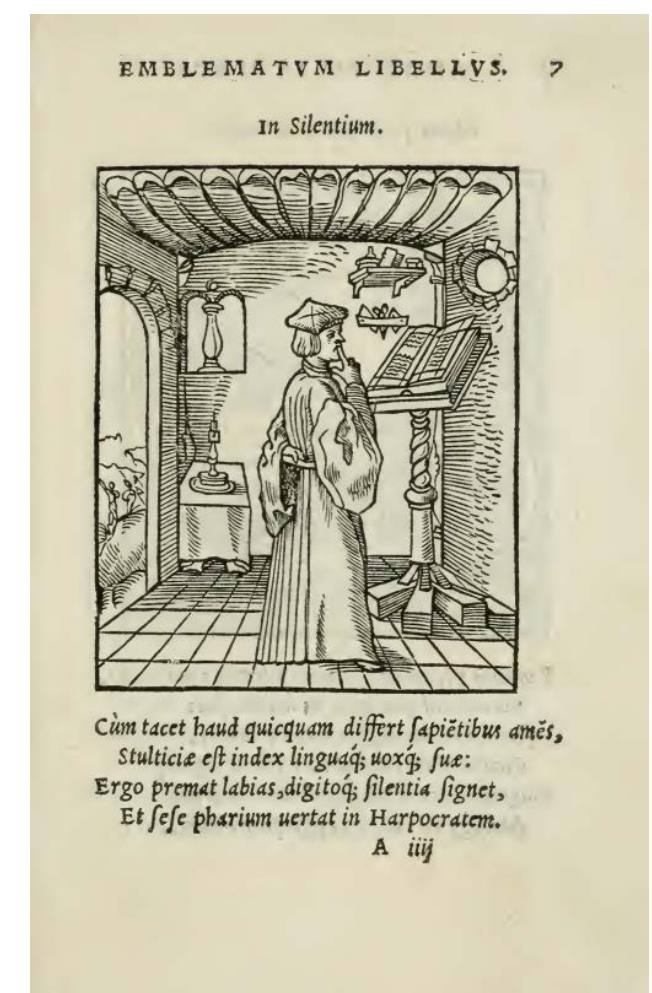

Figure 2: Andrea Alciato, "Silence", from the Emblematum libellus (1531 Wechsel edition). Book in the public domain.

\section{Intertextuality and willful extraction from original context}

Memes are commonly observed to be intertextual: they point to multiple references at once as they riff upon current events and other subjects. The "Distracted Boyfriend" meme in Figure 1 plays upon the turn of young people towards left-leaning politics under the Trump presidency. Yet intertextuality is a common characteristic of emblems as well: Figure 2, for example, employs the common contemporary iconographic trope of the scholar in his study; the text, however, councils silence to the reader so that one might not broadcast one's foolishness-like someone from Pharos, home of the famous lighthouse which illuminates all things-but rather keep one's thoughts to one's self, like Harpocrates, and thus retain the aura of wisdom (Alciato, 1548:14). ${ }^{1}$ The emblem therefore intertextually mixes contemporary iconography and classical imagery. Memes and emblems share this intertextuality: the maker of each extracts their source material and bends that material to their will to meet their chosen significance "with whatever violence" to the source (Manning, 2002:49).

\section{In-group/out-group dynamics}

A common characteristic of meme culture is that they evolved through hyperlocalized contexts arising in online venues such as images boards and social media threads, many of which are deeply ephemeral in nature (Nagle, 2017; Beran, 2019). They are not typically intended for outside consumption by outsiders or "normies", and many in fact are willfully obscure to alienate outside audiences. A similar dynamic was at play

\footnotetext{
${ }^{1}$ The epigram is a precursor to the better-known line attributed to Abraham Lincoln, "Better to remain silent and be thought a fool than to speak and to remove all doubt".
} 
with emblems. Often rendered in Latin, their language acted as a gatekeeper. In addition, emblem-makers took great pains to mix familiarity and obscurity "so that a Sibyl would not be required to interpret its intent, but nor should it be so clear that just anyone could read it" (Giovio, 1559:9).

\section{New media contexts and reception}

Both emblems and memes arose within a comparatively early point in the evolution of their respective information revolutions. Emblems were a popular production of printing, which afforded a wide dissemination of this new format of expression (Eisenstein, 1979). Memes arose out of multiple early social media contexts, taking advantage of the increased democratization afforded by the pervasive networking of the modern Internet. Neither memes nor emblems have been widely respected as a form of expression. Emblems were considered a toy even by their most prominent makers, albeit a toy with serious undercurrents, as the phrase ex nugis seria (out of trifles, serious things) attests (Cats, 1712:237). Despite their popularity, however, emblems became increasingly perceived as simplistic children's moral literature (Manning, 2002:150-52). Likewise, memes are widely deemed to have a corrosive, reductive effect on any they touch, and yet remain widely popular.

\section{Conclusion}

Emblems and memes display unexpected parallels which invite further exploration: formal characteristics, juxtaposition, multimodality, intertextuality, willful recontextualization, devotion to in-group obsessions, obscurity, exploitation of the affordances of their respective media, and decreased regard as they spread beyond their original confines. Each displays an ongoing interest in a more democratized form of communication-whether to express something heartfelt, make a performative statement, or simply share an in-joke-in the context of simultaneous popularity and disdain. The phrase ex nugis seria (out of trifles, serious things) arises out of the history and reception of emblems, but it very much applies to memes as well.

\section{References}

Alciato, A. (1531) Emblematum libellus. Paris: Chrestien Wechsel. [Online] [Accessed on 1 April 2021] https://archive.org/details/alciatiemblematv00alci/mode/2up

Alciato, A. (1953) Le lettere di Andrea Alciato giureconsulto. Barni, G. L. (ed.) Florence: Felice Le Monnier.

Beran, D. (2019) It Came from Something Awful. New York: All points.

Cats, J. (1712) Alle de wercken van den Heere Jacob Cats. Amsterdam: J. Ratelband. [Online] [Accessed on 2 April 2021]

https://archive.org/details/JSH.31962001408628Images/mode/2up

Dawkins, R. (1976) The Selfish Gene. 1989 ed., Oxford: Oxford University Press.

Eisenstein, E. L. (1979) The Printing Press as an Agent of Change. 1982 ed., Cambridge: Cambridge University Press. 
Giovio, P. (1559) Dialogo dell'imprese militari et amorose. Lyon: Guillaume Rouillé. [Online] [Accessed on 1 April 2021]

https://archive.org/details/impresemilitarie00giov/mode/2up

Manning, J. (2002) The Emblem. 2004 ed., London: Reaktion.

Milner, R. (2016) The World Made Meme: Public Conversations and Participatory Media. Cambridge: MIT Press.

Nagle, A. (2017) Kill All Normies: Online Culture Wars from 4Chan to Tumblr and the Alt-Right. Winchester: Zero Books.

Shifman, L. (2014) Memes in Digital Culture. Cambridge: MIT Press.

Wiggins, B. E. (2019) The Discursive Power of Memes in Digital Culture. London: Routledge. 